\title{
Research and Design Voice Control Camera using Raspberry PI
}

\author{
V.Janani R. Puviarasi Mritha Ramalingam, S.R.Boselin Prabhu
}

\begin{abstract}
Today we are building a valuable venture in which we can control the LED lights utilizing our voice through Smart Phone. In this undertaking, we will send voice directions from Smart Phone to Raspberry Pi utilizing Bluetooth Module and Raspberry $P i$ will get that transmitted flag remotely and will perform separate assignment over the equipment. We can supplant the LEDs with the AC home machines utilizing transfers and can fabricate a Voice Controlled Home Automation Project. This paper basically worried about the programmed voice control of light or some other home machines. It is utilized to spare the electric power and human vitality. This task is made with assistance of Raspberry Pi 3 and Relay driver circuit. The different machines are associated with the transfer circuit and the mouthpiece associated with Raspberry $\mathrm{Pi}$ 3. After fruitful acknowledgment of voice direction the Raspberry Pi 3 drives the comparing machines. Voice acknowledgment is created by utilizing Google API's.

Keywords-IOT, motor drive, raspberry pi, camera, bylnk app, power supply
\end{abstract}

\section{INTRODUCTION}

Security is ending up increasingly basic for Android advanced cell because of the expansion in number of overall clients that include delicate individual data in their telephones. Programmers or the individuals who abused vulnerabilities in Android are finding better approaches to assault through Android applications. The expanding difficulties to verify Android framework are because of the distinctive application authorizations and highlights to clients. Android security goes past the antivirus highlights. Greatest hazard to Android clients and the fundamental motivating force to download a security application, infections aren't the best danger [1-5].

Android 4.1.1 variant has heart drain hazard that implies client data rupture utilizing powerless applications introduced on their advanced cell . Our proposed work isn't identified with such sort of data break on the grounds that as an answer for this many shrewd antivirus, applications are free accessible. Rather than that we have centered to keep the data rupture that is conceivable because of burglary of Android gadget. Numerous clients store their critical individual data including essential records. This sort of private data might be open by cheat and it might be utilized for individual use or uncovered to world by means of web.

Revised Manuscript Received on July 18, 2019.

V.Janani, Department of ECE, Saveetha Institute of Medical and Technical Sciences, Chennai

R. Puviaras, Department of ECE, Saveetha Institute of Medical and Technical Sciences, Chennai

Mritha Ramalingam, Faculty of Computer Systems \& Software Engineering Universiti Malaysia Pahang Gambang, Malaysia

Dr.S.R.Boselin Prabhu, Associate Professor, Department of Electronics and Communication Engineering, Surya Engineering College, Mettukadai, India
This must be prevented using any sort of instrument. On the off chance that we consider second kind of assault that is gadget robbery, we can see that data break is getting to be conceivable not essentially on the grounds that your gadget is burglary. It is on the grounds that you don't have authority over your gadget information after robbery. Robbery of gadget and client data break is some way or another identified with one another. In the event that client has authority over gadget to get to its area and put away data then data break can be avoided even after gadget burglary [6-7]. To give this sort of control after robbery of gadget, we will build up a system that will work in any sort of circumstance. In the event that gadget isn't running on web association, at that point additionally component will work. The Raspberry Pi has no worked in soundcard or sound jack, so you need a USB mouthpiece or a webcam with inherent amplifier for this undertaking. We tried the product utilizing a Microsoft HD-3000 webcam, however any good gadget will do. Visit there's a full rundown of Raspberry Pi-perfect webcams in the event that you don't as of now have one, yet make certain that whatever gadget you pick has a coordinated receiver. See whether you can discover a USB receiver or webcam In the event that you just have a mouthpiece with a sound jack, take a stab at looking Amazon or eBay for an economical USB soundcard, which connects to the USB port toward one side and has a yield for headphones and an amplifier at the other. There's various discourse acknowledgment programs for the Raspberry Pi. For this venture, we're utilizing Steven Hicks on's Pi AUI Suite, since it's ground-breaking just as incredibly simple to set up and design. The Jasper framework, despite the fact that it works disconnected, bargains exactness and speed. This would be helpful for frameworks that have no entrance to the web, however. A little admonition: The framework takes up just about an entire 4GB memory card, so use somewhere around a $8 \mathrm{~GB}$ card with it. A portion of its administrations are awkward and require a great deal of exertion from the client to articulate over and over until the framework lifts it up. The virtual products exhibited by Oscar and Steven use Google voice APIs, they are exact and exact. Them two likewise use Google discourse, so the framework can be controlled to argue and react to your directions and inquiries. In any case, I lean toward the third programming since it has a basic and direct interface. Here, you will most likely characterize every one of your voice directions and connection them to specific errands as slam directions. These are characterized inside a design record. 


\section{WORKING PRINCIPLE}

The product being depicted here utilizations Google Voice and discourse APIs. The voice direction from the client is caught by the mouthpiece. This is then changed over to content by utilizing Google voice API. The content is then contrasted and the other recently characterized directions inside the directions setup document. On the off chance that it matches with any of them, the slam direction related with it will be executed. You can likewise utilize this framework as an intelligent voice reaction framework by influencing the Raspberry Pi to react to your directions by means of discourse. This is accomplished by utilizing the Google discourse API, which changes over the content into discourse. Here's a square outline demonstrating to you the essential working of the voice acknowledgment programming for Raspberry Pi: You have to initially check whether your mouthpiece records appropriately. To begin with, check if your webcam or receiver is recorded utilizing the order "lsusb".

\section{BLOCK DIAGRAM}

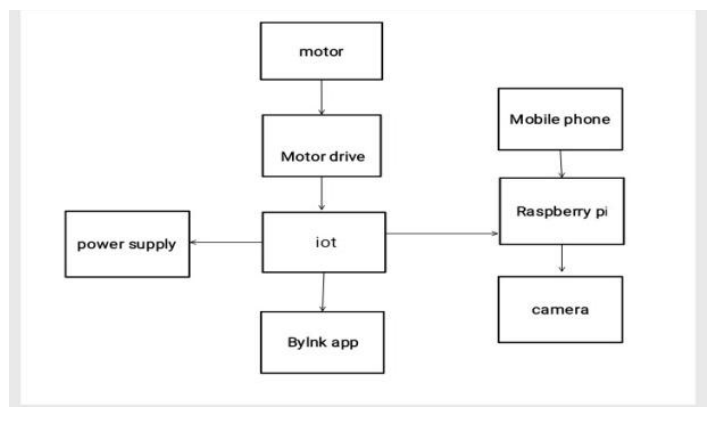

\section{PROPOSED SYSTEM}

In the wake of losing gadget client don't have physical authority over it. Thus, client will send diverse directions to Android gadget so as to control the gadget tasks. Client will send this directions utilizing telephone SMS. To begin following the gadget we need to simply send one SMS like "Begin TRACKING" to initiate disconnected area track- ing administration. This order of course naturally additionally begin the various administrations that are required after gadget burglary. On the other hand, client can likewise accomplish the equivalent after login through web server utilizing web ask for mechanism(by squeezing begin administrations catch) however that isn't much dependable as it requires running web association on Android gadget. By and large it is attractive to utilize both of the choices at the same time. The proposed model work with or without web association with begin or stop application benefits after the cell phone is robbery.

\section{TESTS AND RESULTS}

To control the outlet, all you truly need is a switch. I additionally incorporated a catch to use with Speech kit to that the outlet can be controlled utilizing voice directions. To make the parts, open Main. Storyboard in Xcode. In the toolbar on the correct side of the screen, demonstrate the item library by tapping on its symbol.

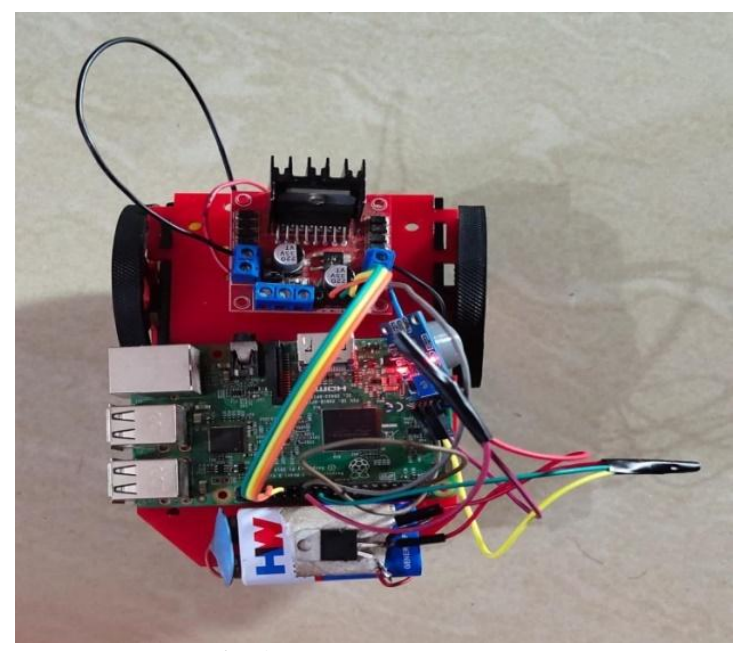

Fig 2: hardware output

Drag a catch and a switch onto the storyboard and mark them suitably. Redo the page to your enjoying utilizing distinctive hues, textual styles, and separating. Here's a look of my completed item. At long last, you have to interface your UI components to your code. Ensure you're utilizing the associate editorial manager by choosing the suitable symbol at the highest point of the page. You ought to have both Main. Storyboard and View Controller, swift obvious. In View Controller, swift, Hold the control key while you click the Listen catch on your storyboard, at that point drag it to your View Controller class. Name the catch, yet don't change any of alternate settings. Do likewise for your switch, so you can without much of a stretch reference it later.

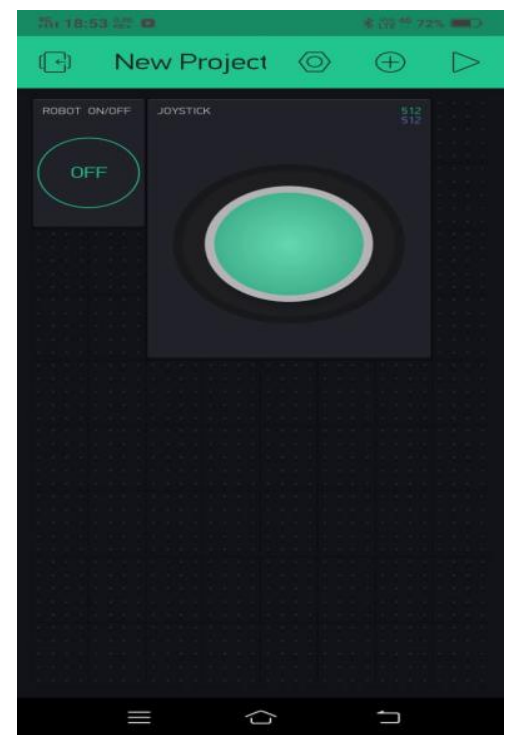

Fig 3: Jaystick control robot using bylnk app

Presently control-drag the catch and the switch once more, yet this time change Connection to Action. This will enable you to make works that are possibly considered when each catch is pushed, which you're currently prepared to do. this is in reality entirely basic utilizing SpeechKit from Nuance Developers. They give all of you the capacities you 
need, you simply need to incorporate them in your application and change them for your necessities.

When you have every one of your qualifications settled, you have to characterize the representative in the class header.

\section{PROS AND CONS}

Taking pictures in DSLR for many people is quite difficult and taking self pictures is more complex. Adjusting the correct angle according to the light exposure is the biggest task. To overcome these problems, I control the DSLR using Raspberry Pi by Voice recognition method.

\section{CONCLUSION}

Application distinctive administrations will create information and data that will be sent through web demand to webserver. Area refreshes give client area of gadget. This arrangement of areas will make one way or spot of visit visiting place. Pictures with geo-labeling will offer intimation to client to distinguish criminal character and ready to get each picture's area and date-time data.

\section{REFERENCES}

1. Victor, H. (2014) Android's Google Play Beats App Store with over 1 Million Apps, Now Officially Largest.

2. Llamas, R., et al. (2015) Smartphone OS Market Share, 2015 Q2. IDC Report August 2015. http://www.idc.com/prodserv/smartphone-os-market-share.jsp

3. Warren, C. (2014) Android 4.1.1 Devices Are Vulnerable to Heartbleed.

4. Chauhan, J.G. and Modi, P.S. (2015) A Novel Approach to Real Time Health Monitoring System. Journal of Multidisciplinary Research Studies, 1, 78-80.

5. Wu, L.F. and Du, X.J. (2014) Security Threats to Mobile Multimedia Applications: Camera-Based Attacks on Mobile Phones. IEEE Communications Magazine, 81, 80-87.

6. Park, J.-K. and Choi, S.-Y. (2015) Studying Security Weaknesses of Android System. International Journal of Securityand Its Applications, 9, 7-12.

7. Hidayatul Nur Binti Hasim, Mritha Ramalingam, Ferda Ernawan, Puviarasi .R, "Developing fish feeder system using Raspberry Pi". 3rd International Conference on Advances in Electrical, Electronics, Information, Communication and BioInformatics (AEEICB17) 